\title{
Falling Off the Edge
}

\section{Citation}

Inouye, Sharon K., James J. O'Connell, and Margaret R. Puelle. 2013. "Falling Off the Edge." JAMA 309 (5) (February 6): 451. doi:10.1001/jama.2012.214089.

\section{Published Version}

doi:10.1001/jama.2012.214089

\section{Permanent link}

http://nrs.harvard.edu/urn-3:HUL.InstRepos:33750340

\section{Terms of Use}

This article was downloaded from Harvard University's DASH repository, and is made available under the terms and conditions applicable to Other Posted Material, as set forth at http:// nrs.harvard.edu/urn-3:HUL.InstRepos:dash.current.terms-of-use\#LAA

\section{Share Your Story}

The Harvard community has made this article openly available.

Please share how this access benefits you. Submit a story.

\section{Accessibility}




\section{Falling Off the Edge}

O

NE EVENING AS I (S.K.I.) WAS CLEARING THE TABLES in the soup kitchen where I was volunteering, I struck up a conversation with a homeless man. With his long white beard, stooped posture, and limping gait, I was sure he was older than 70 years. I was surprised to learn he was only 48 . As a geriatrician with more than 25 years of clinical experience, I am usually pretty good at telling how old someone is. But after this scenario repeated itself several times, I began to wonder whether chronic homelessness might be associated with accelerated aging. Could exposure to the elements and the constant stress of the relentless daily struggle to survive lead to more rapid aging, along with its attendant functional and cognitive decline?

With this question in mind, I approached a colleague (J.J.O.) at the Boston Health Care for the Homeless Program (BHCHP), someone who had long inspired me with his work establishing an extensive health care network serving the Boston homeless population. I inquired whether he thought the idea of accelerated aging in the chronically homeless population was a real phenomenon, and without hesitation, he agreed. I asked if I could volunteer as a physician in his program to provide functional and cognitive assessments-the special skills of the geriatrician-to explore this area further.

Thus began a great adventure of exploration. I saw patients with frequent falls, severe depression, violent behavior, and unspecified memory problems. For some patients, homelessness was the result of well-recognized and oftcited contributors, including poverty, loss of employment, use of alcohol and other drugs, mental illness, and undertreated chronic illnesses. The phenomenon of accelerated aging was pervasive. However, I was caught unaware by an even more important aspect of aging: that cognitive decline often plays a prominent yet unappreciated role in contributing to homelessness. For me, three cases in particular served to bring this reality to the fore.

The first case was a former teacher in her 70s with mild diabetes mellitus and a remote history of head trauma, who had been living on her own until 18 months ago. She found that she could no longer stretch her \$1000/month fixed income to cover her expenses and rent. She took to traveling from town to town, living at bus stations, occasionally finding cleaning jobs, chores, or kind people who would take her in. She had significant deficits in executive functioning (clock-drawing, Trails B), naming, and delayed recall, and she was diagnosed with probable Alzheimer-type dementia. She had been able to subsist at poverty level until her cognitive deficits progressed to the point where she could no longer live independently. She will now require nursing home placement.

The second case was a high school graduate and former truck driver in his 70s with multiple chronic conditions, including severe asthma, hypertension, diabetes mellitus, heart failure with a pacemaker for heart block, alcohol abuse, and chronic anxiety. He had been living with family out of state but moved to escape an abusive situation over a year ago. He has recently been placed in a program for the chronically homeless, but experiencing difficulty managing his medications, special diet, and doctors' appointments. He had become a "frequent flier," with numerous emergency department and hospital admissions for exacerbations of his medical conditions. His examination reveals evidence of severe wheezing and bibasilar rales, with mild to moderate impairment of executive dysfunction defined below (eg, verbal fluency, abstraction, and Trails B) and marked short-term memory deficits. His diagnosis is mild cognitive impairment due to multifactorial contributors, including alcohol, head trauma, and microvascular disease. He is failing in his current unsupervised living situation and is now being referred for nursing home placement.

The third case is a married woman in her late 40s with a grammar school education who suffers from hypertension, hyperlipidemia, diabetes mellitus, depression, alcohol abuse, and frequent falls. She reports life-long learning and functional limitations that have progressively worsened over the past 2 years. She was living independently and providing care for her husband, with a heart condition, until they lost their health insurance when they were living out of state. They moved to Boston about a year ago and have been living in separate shelters, since the Boston shelters cannot accommodate couples. Her physical examination reveals facial features and habitus consistent with fetal alcohol syndrome. Cognitive testing reveals severe global cognitive impairments in all domains tested, with the most severe impairments in executive function. Thus, she demonstrates lifelong poor intellectual performance due to mild mental retardation, now exacerbated by progressive impairment likely due to microvascular disease. She and her husband have now entered the world of chronic homelessness.

As these cases highlight, cognitive decline may contribute to chronic homelessness, defined by the US Department of Housing and Urban Development as either being continuously homeless for a year or more or having had at least four episodes of homelessness in the past three years, ${ }^{1}$ by precipitating homelessness and by influencing the level of supportive housing that may be required. Cognitive decline is on the rise for several reasons. First, the homeless population is aging even more rapidly than the rest of the US population ${ }^{2}$; fully one-third of the current homeless population is older than 50 years, compared with $11 \%$ in the 1990s. ${ }^{3}$ Associated with this aging are rising rates of cognitive impairment and dementia. Based on cognitive screening tests, global cognitive impairment has been identified in about $4 \%$ to $7 \%$ of all homeless adults with rates increas- 
ing to more than $24 \%$ in those aged 50 to 69 years. ${ }^{4}$ The etiology of the observed cognitive impairment is likely multifactorial, including factors such as substance abuse, traumatic brain injury, mental illness, progressive dementia, other underlying neurological disorders, developmental disabilities, malnutrition, and undertreated chronic illness. ${ }^{5}$

Many cognitively at-risk adults appear to be subsisting in a barely compensated stage until cognitive decline pushes them "over the edge." Persons with chronic cognitive impairment, such as from developmental disabilities or fetal alcohol syndrome, often find ways to cope and live independently despite their impairments. However, the addition of age-related cognitive decline or dementia can precipitate homelessness. Studies have shown that a decline in cognitive functioning from a previous level regardless of that level was strongly predictive of chronic homelessness, whereas the current degree of cognitive impairment was not. ${ }^{6}$ Executive dysfunction represents the most common cognitive domain affected ${ }^{4,5}$ and is defined by impairment of cognitive abilities that control and regulate other abilities and behaviors. Thus, executive dysfunction can result in impairment in the ability to plan and complete activities such as keeping appointments or taking medications.

What are the implications of the rise in cognitive decline among the homeless population? First, studies have shown that homeless individuals with cognitive decline are less likely to use traditional health and social services. ${ }^{7}$ Second, without strategies to recognize, intervene, or provide appropriate support, efforts to avoid or end homelessness will fail in this group. Shelter alone will not be sufficient or appropriate to address homelessness in this growing segment of the population. Efforts to better detect cognitive decline and to implement appropriate intervention strategies will be critical. ${ }^{8}$ However, current supportive housing programs are ill equipped to meet the special needs of cognitively impaired individuals, who are likely to fall between the cracks. Programs that simply provide meals and a bed will not be adequate to maintain health and independence. While these individuals can no longer live independently, they may not necessarily require nursing home placement that is often the only alternative in many communities. In addition, many homeless individuals will not agree to nursing home placement, where they lose their independence and access to their disability checks. Thus, an intermediate level providing a modest degree of supervision may be necessary to maintain independent living for these individuals.

For the most part, those with early-moderate executive dysfunction will be able to get by with management of medication and finances, in addition to the meals and shelter that are commonly provided. A program such as a "house mother," group home program, or a board and care facility with a modest degree of supervision would be enough to allow many individuals to remain living in the community for many years. However, the programs will need to be flexible to meet the needs of this diverse population, offering both group and individual options. While such programs have been used in schizophrenia and other severe mental illnesses, they have not been applied to help homeless individuals with cognitive impairment. In addition to these supportive services, specific cognitive interventions such as life-skills training and cognitive rehabilitation may offer additional benefits to help keep these individuals off the streets. ${ }^{9}$

Through this great adventure, I have confirmed my initial impression about accelerated aging in the homeless population, yet more importantly, I realized the substantial role that cognitive impairment may play in contributing to chronic homelessness. The initial thrill of discovery, however, has been replaced by the solemn awareness of the pressing need to find ways to provide appropriate care for this newly recognized and highly vulnerable segment of our population. Given the aging of the population, the problem of cognitive decline is likely to rise dramatically in the near future and profoundly change the face of homelessness in the United States. Without a concerted effort by advocates for the homeless population, health care professionals, and policy makers to improve recognition of cognitive impairment, both to prevent chronic homelessness and to implement appropriate housing and supportive strategies, our society may be caught unprepared in an extremely costly, escalating battle to provide care to the rapidly aging homeless population.

Sharon K. Inouye, MD, MPH

James J. O’Connell, MD

Margaret R. Puelle

Author Affiliations: Department of Medicine, Beth Israel Deaconess Medical Center, Harvard Medical School (Dr Inouye; agingbraincenter@hsl.harvard.edu); Aging Brain Center, Institute for Aging Research, Hebrew SeniorLife (Dr Inouye and Ms Puelle); Department of Medicine, Massachusetts General Hospital, Harvard Medical School (Dr O'Connell); Boston Healthcare for the Homeless Program (Drs Inouye and O'Connell); Boston, Massachusetts.

Author Contributions: The experiences described herein are those of the first author (S.K.I.), and the draft was developed with extensive discussion and editing by the coauthors (J.J.O., M.R.P.).

Acknowledgment: This work is dedicated to the memory of Joshua Bryan Inouye Helfand.

Conflict of Interest Disclosures: All authors have completed and submitted the ICMJE Form for Disclosure of Potential Conflicts of Interest; none were reported.

1. Witte P. The State of Homelessness in America 2012. Washington, DC: National Alliance to End Homelessness; 2012.

2. Culhane DP, Metraux S, Bainbridge J. The Age Structure of Contemporary Homelessness: Risk Period or Cohort Effect? Philadelphia, PA: Penn School of Social Policy and Practice Working Paper 2010.

3. Hahn JA, Kushel MB, Bangsberg DR, Riley E, Moss AR. The aging of the homeless population. J Gen Intern Med. 2006;21(7):775-778.

4. Brown RT, Kiely DK, Bharel M, Mitchell SL. Geriatric syndromes in older homeless adults. J Gen Intern Med. 2012;27(1):16-22.

5. Burra TA, Stergiopoulos V, Rourke SB. A systematic review of cognitive deficits in homeless adults. Can J Psychiatry. 2009;54(2):123-133.

6. Bremner AJ, Duke PJ, Nelson HE, Pantelis C, Barnes TR. Cognitive function and duration of rooflessness in entrants to a hostel for homeless men. Br J Psychiatry. 1996;169(4):434-439.

7. Geddes JR, Newton JR, Bailey S, Freeman C, Young G. Prevalence of psychiatric disorder, cognitive impairment and functional disability among homeless people resident in hostels. Health Bull (Edinb). 1996;54(3):276-279.

8. Joyce DP, Limbos M. Identification of cognitive impairment and mental illness in elderly homeless men. Can Fam Physician. 2009;55(11):1110-1111.e6.

9. Helfrich CA, Chan DV, Sabol P. Cognitive predictors of life skill intervention outcomes for adults with mental illness at risk for homelessness. Am J Occup Ther. 2011;65(3):277-286. 